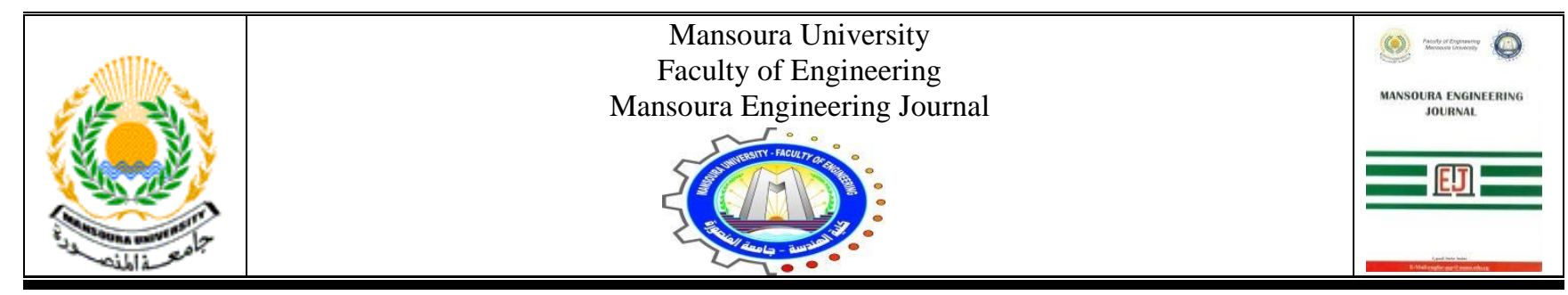

\title{
Types of Faltering Government Projects (Case Studies in the Qassim Region)
}

\author{
Mohammed Ahmed Al-Thuwaini and Abdulaziz Ibrahim Alhrabi
}

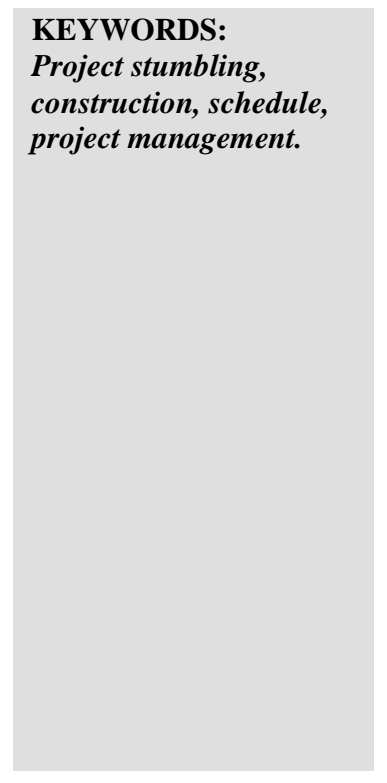

\begin{abstract}
The construction sector in the Kingdom of Saudi Arabia is considered one of the most important sectors, yet we find that most government projects suffer from stumbling in the implementation resulting in an increase in cost and time period. The research problem lies in the presence of faltering government projects in the construction sector, and it is important to know the types of causes of these faltering government projects so that they can be avoided in the future. Where the research methodology was based on previous studies related to projects and track the study cases of troubled government projects and their description in the Qassim region, and the comparison to see similarities.

The research included an analysis of the tracked study cases and collected from several sources, where ten (10) cases of stumbling government projects in the Qassim region were reviewed. The results indicate that there are many different types of projects stumbling in the construction sector, which are classified according to the project parties (the owner, the consultant, the contractor) and according to the sections of the projects timeline (civil, architectural, mechanics, electricity), where the owner formed the highest The percentage of delayed financial extracts $(\mathbf{8 0 \%})$, while the Electricity Department (55\%), the Architectural Department (25\%), and the Mechanics Department (31\%)
\end{abstract}

المشاريع الحكومية المتعثرة في الإنجاز في الوقت المحدد، حيث إنه في عام 2018

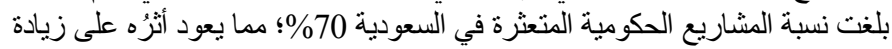

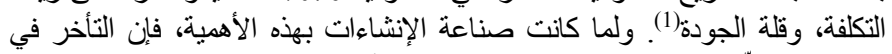

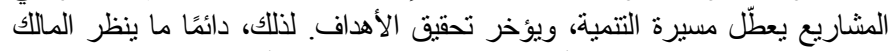

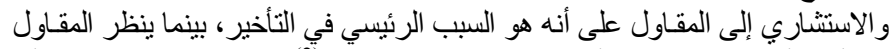

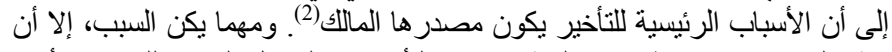

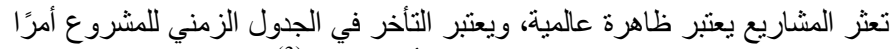

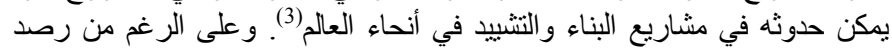

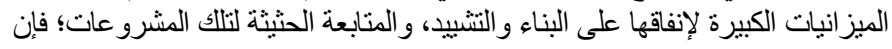

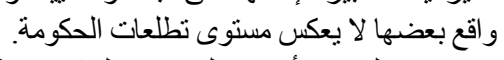

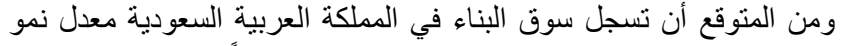

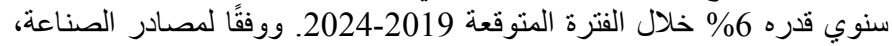
هنالك أكثر من 5200 مشروع بناء قيد التنفيذ في المملكة العربية السعودية بقيمة

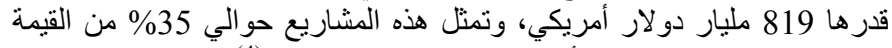

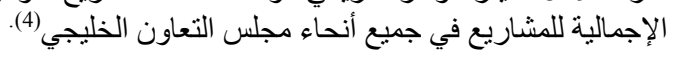

Received: (10 June, 2020) - Revised: (12 November, 2020) - Accepted: (24 November, 2020)

Mohammed Ahmed Al-Thuwaini (Master student), Department of architecture, Works at project management, Qassim University, Saudi Arabia (K.S.A.) (m.a.m.16@hotmail.com).

Corresponding Author: Abdulaziz Ibrahim Alhrabi, Associate Professor at Department of Architecture and Planning, Qassim University, Saudi Arabia (K.S.A.). Ph.D. in Architecture Philosophy, specializing in building and Construction Sciences, Master of Architecture and Construction Science, and Master of building and Construction Engineering (alhrabi@qu.edu.sa). 
أنشار (Al-Dmaidi,2013) في دراسة إلى أسباب تأخر مشروعات

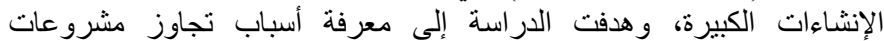

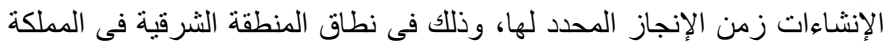

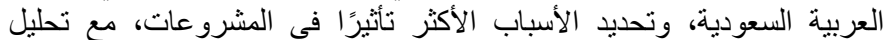

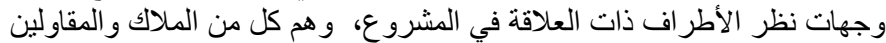

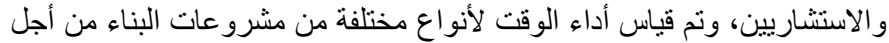

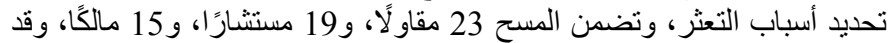

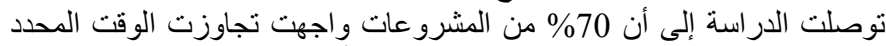

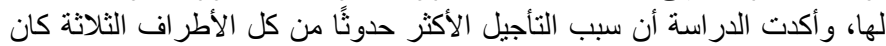
تغييرًا في الأو امر (9). أجرى (Albogamy,2012) دراسة عن توضيح الاريح أهم أسباب تأخير

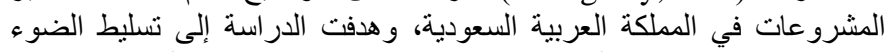

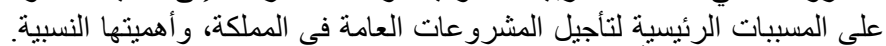

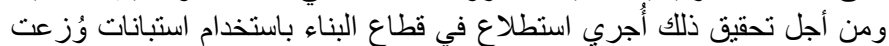

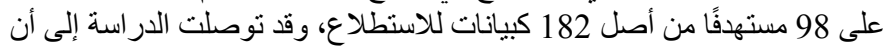

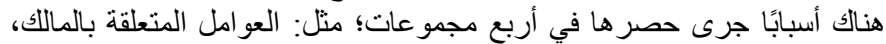

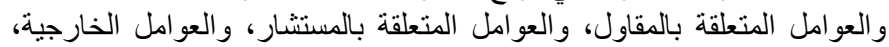
وكان أحد أكثر العو امل تأثيرًا في التأجيل هو مالك المشروع (10).

\section{مفهوم إدارة المشاريع وممراحلها}

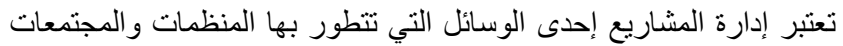

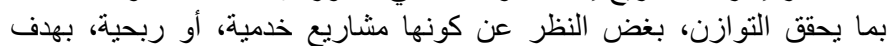

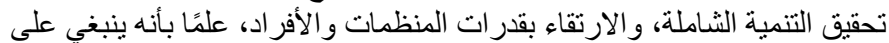

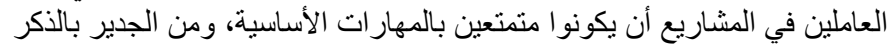

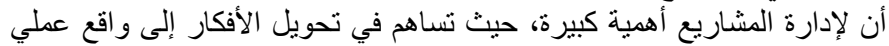

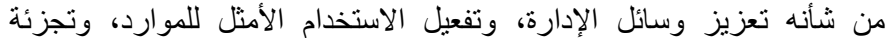

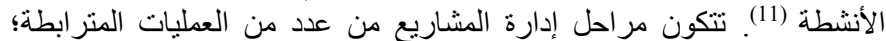

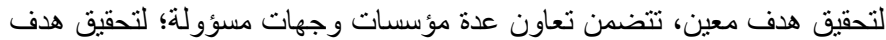

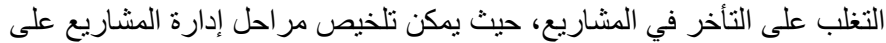

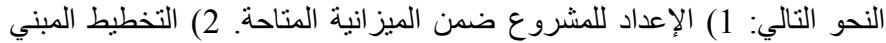

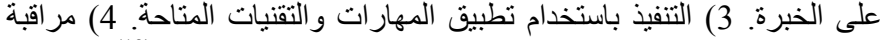

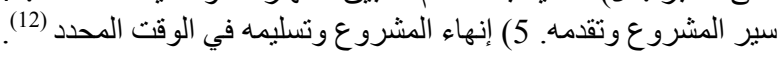

\section{مراحل تكوين المشروع V VIII}

تتكون دورة حياة الشروع من عدة مراحل، وذلك على النحو التهوع التالي (13): دراسة جدوى المشروع: حيث يتم في هذه المرحلة ابتكار الفكرة التي تتعلق

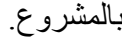

1. التخطيط للمشروع: فيتم نقل الفكرة إلى حيز التخطيط، بحيث يتم توضيح أهداف المشروع، و الأنشطة التي تتعلق بهاه، و الفئات المستفيدة منه. تخصيص الموارد: حيث تتم دراسة الموارد المالية والبشرية اللازمة لتنفيذ التئي

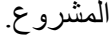
• تنفيذ المشروع: حيث يتم البدء في تتفيذ المشروع، علئا بأن أهمية إدارة المشاريع تظهر من خلال هذه المرحلة.

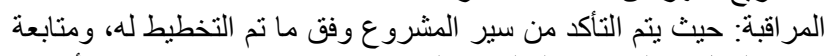
فريق العمل، والجو انب المالية، والموارد جميعها، ومدى تحقيق الأهداف

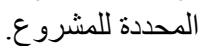

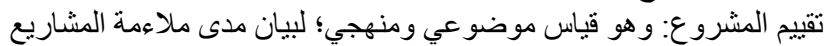

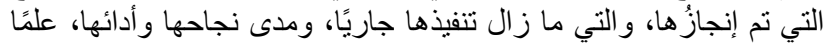

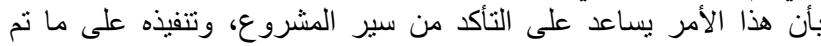

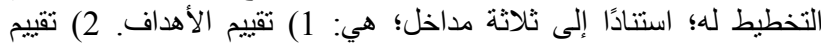
الإجر اءات. 3) ت تقييم النتائج.

\section{IX}

تتكون الهشاريع الهندية من ثلاثة أطراف أساسية للقيام بالمشروع (14):

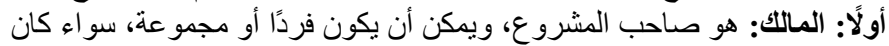

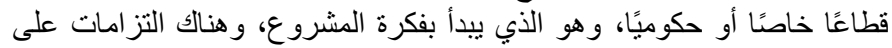

II

يوجد قصور في معرفة أسباب تعثر المشاريع الحكومية، وطرق البحث التعامل

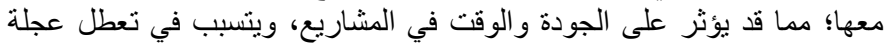
التنمية والنهضة العمر انية، التي تطمح إلى تحقيق رؤية التية المملكة العربية السعودية فيلة

2030

\section{III}

• ما هي أنواع التأخير التي تواجه تعثر المشاريع الحكومية؟

IV

مر اجعة الدراسات السابقة لمعرفة أنو اع تعثر المشاريع الحكومية.

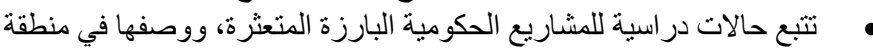
مقارنة بين الحالات الدر اسية؛ لمعرفة أوجه التشابه في تأخير المشاريع.

\section{V ل}

• تسليط الضوء على العو ائق التي تتسبب بتعثر المشاريع الحكومية. معرفة أنواع تأخير المشاريع الحكومية.

\section{VI}

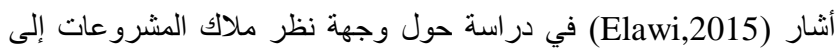

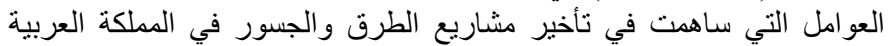

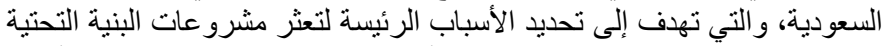

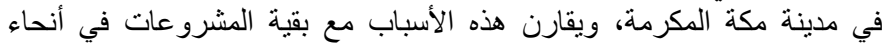

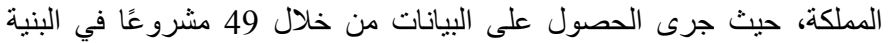

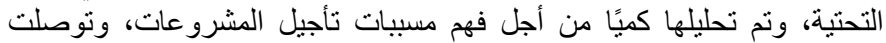

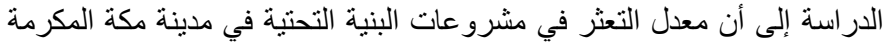

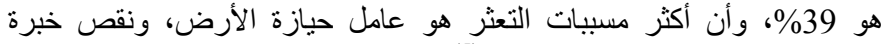

المقاولين، و الخدمات، وإعادة التصميم(5). أشار (Mahamid, 2015) في دراسة إلى تصنيف المخاطر الخاصة بتأخر

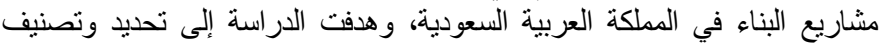

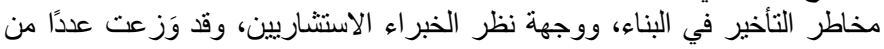

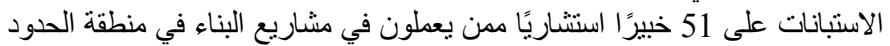

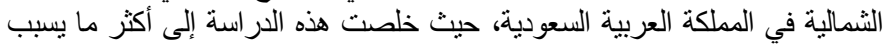

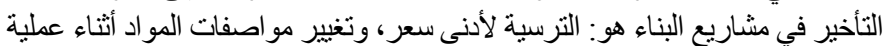

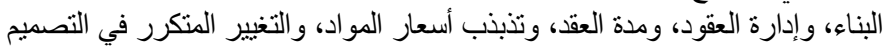

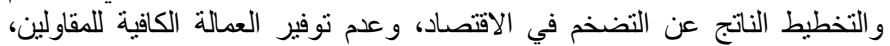

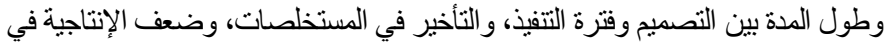
العمل، وتغيير الأوامر (6). ذكر (Albogamy,2013) في دراسة حول معضلة قطاع الإنشاءات في المملكة

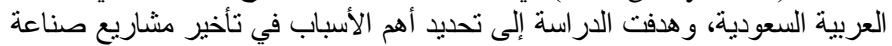

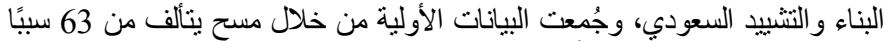

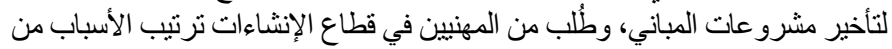

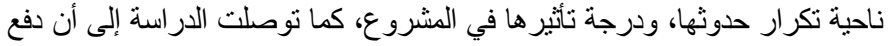

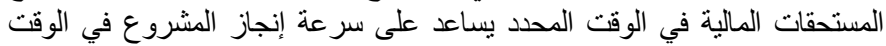

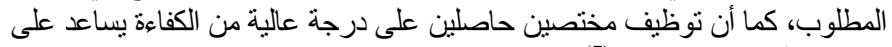

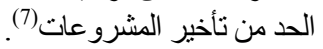

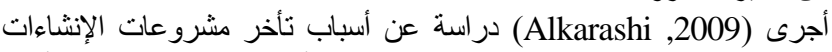

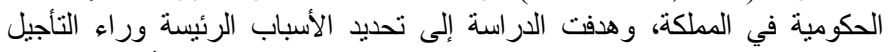

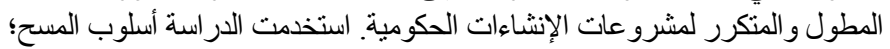

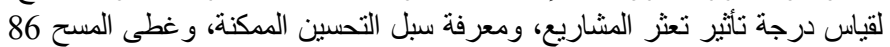

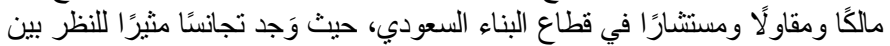

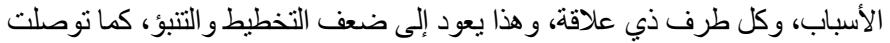

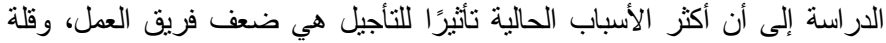

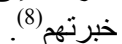


المبلغ يحمّل المقاول كاملَ المسؤولية وأي مخاطر يتعرض لها المشروع أثناء التنفيذ.

2- عقد ثمن الوحدة: يعتمد هذا النوع من العقود على سعر الوحدة لكل بند من

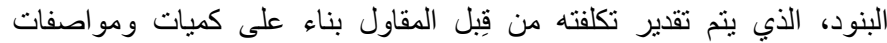

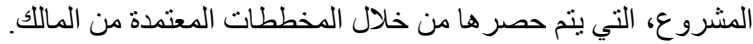

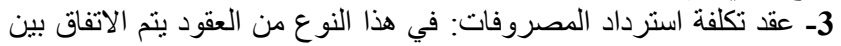

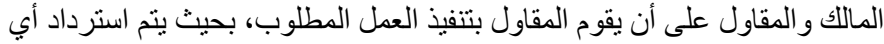

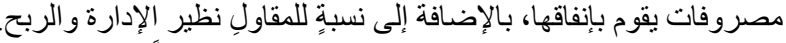

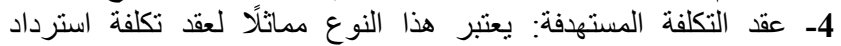

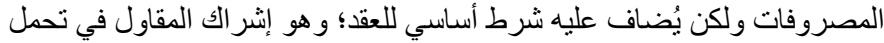

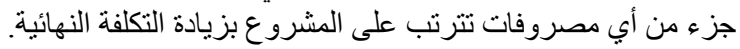

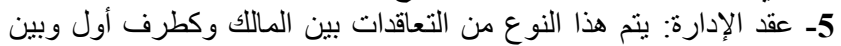

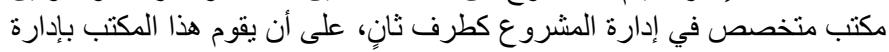
المشروع في جميع مر احله.

\section{XII}

الجدول الزمني هو عبارة عن رسم بياني يوضح مر احل تتفيذ الأعمال، مثل:

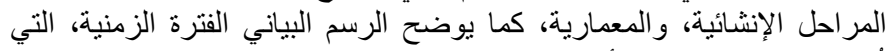

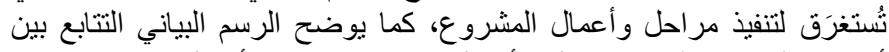

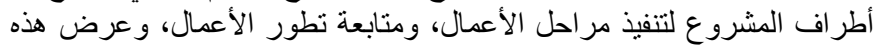

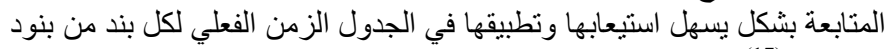

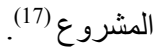

\section{XIII}

تتراوح نسبة تعثّر المشاريع حسب درجة الانحراف عن الخطط الأساسية

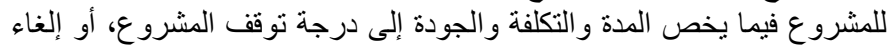

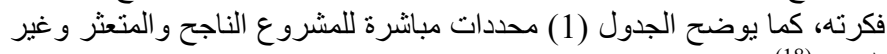

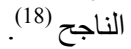

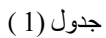

محددات المشاريع الناجحة والمتعثرة وغبر الناجحة الني تحدث في البناءو التشييد (18)

\begin{tabular}{|c|c|c|}
\hline محددات المشاريع & أنواع المشاريع & م \\
\hline 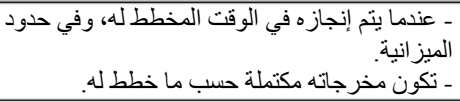 & المشاريع الناجحة & 1 \\
\hline 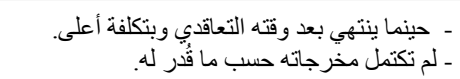 & المشاريع المتعثرة & 2 \\
\hline 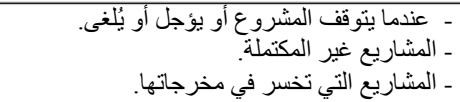 & الناجحة المشع غير & 3 \\
\hline
\end{tabular}

\section{XIV}

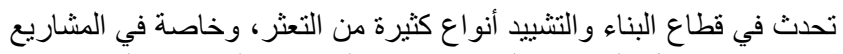

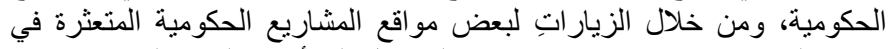

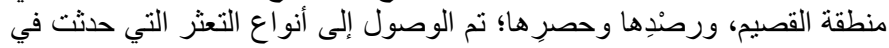

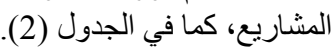

جدول (2) (ل)

وصف حالات التعثر التي حدثت في المشاريع

\begin{tabular}{|c|c|}
\hline الوصف & الحالة \\
\hline 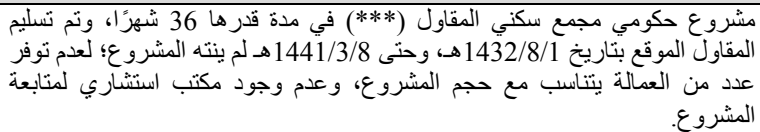 & الأولى \\
\hline 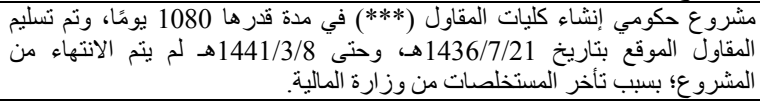 & الثانية \\
\hline 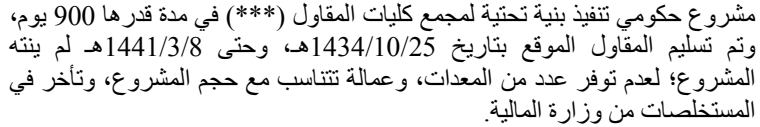 & الثالثة \\
\hline
\end{tabular}

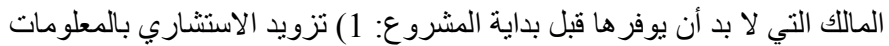

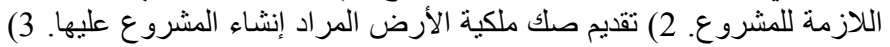

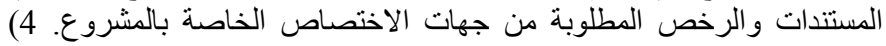

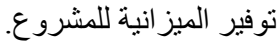

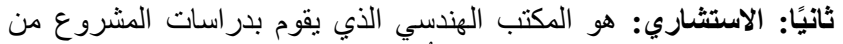

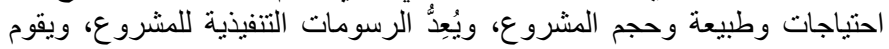

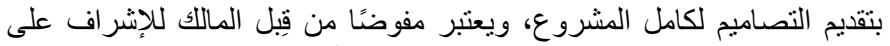

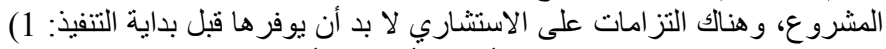

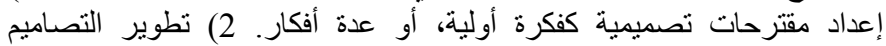

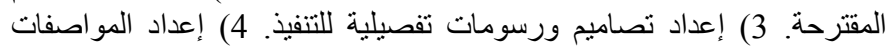

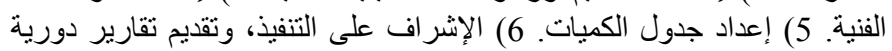

ثالثًا: المقاول: هي الجهة التي تقوم بتنفيذ المشروع، ويؤدي دورَه تحت

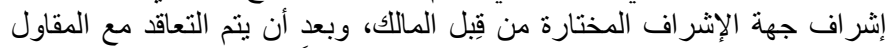

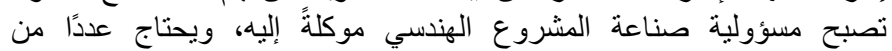

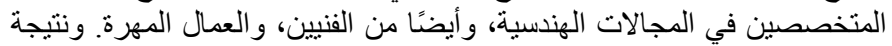

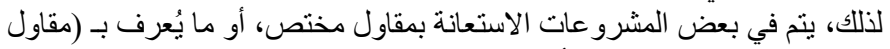

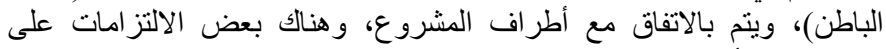
المقاول لا بد أن يوفر ها قبل بداية المبع المشروع:

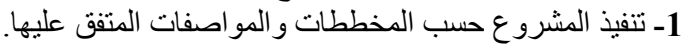

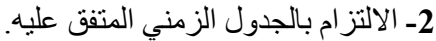

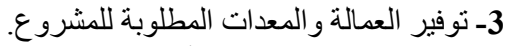
4- الالتز ام بضبط الجودة و الأمن و السلامة بالمشروعة للمنروع.

\section{X}

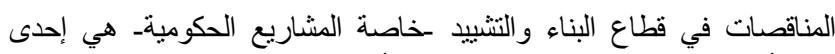

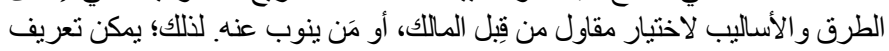

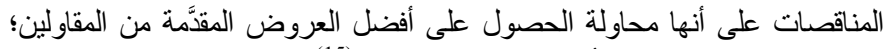

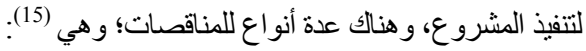

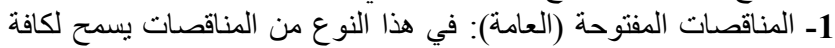

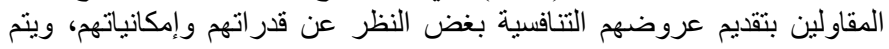

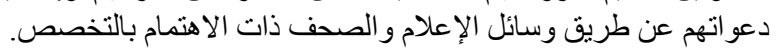

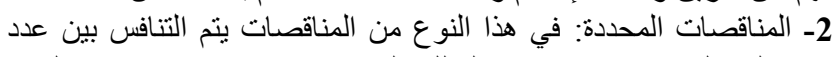

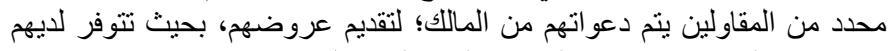

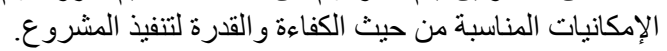

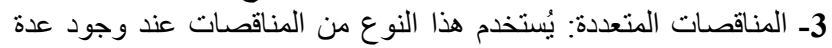

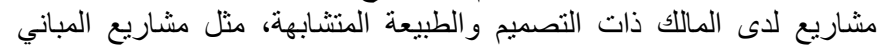

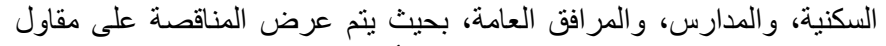

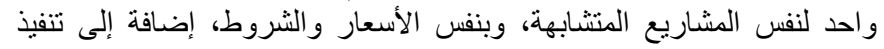

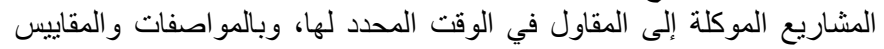
الفنية المتفق عليها.

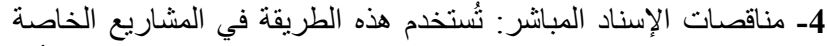

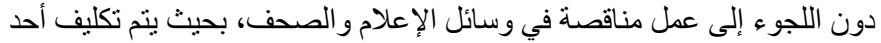

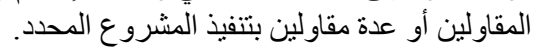

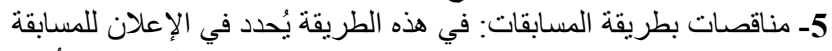

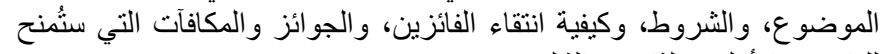
للفائزين؛ الأول، و والثاني، و والثالث.

\section{XI}

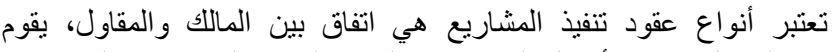

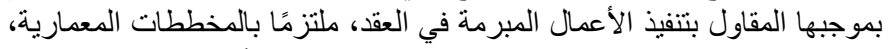

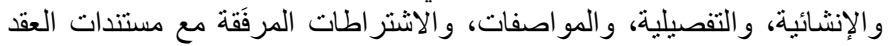

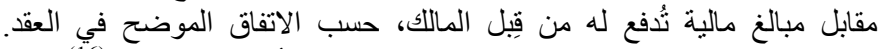

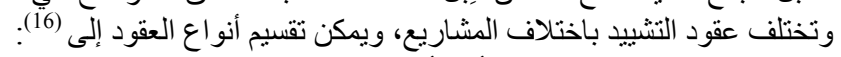

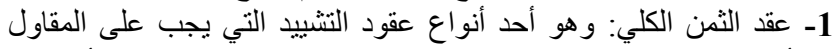

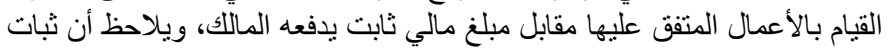




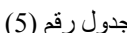

ملخص المشاريع المتعثرة المحددة في الحالات الدراسية

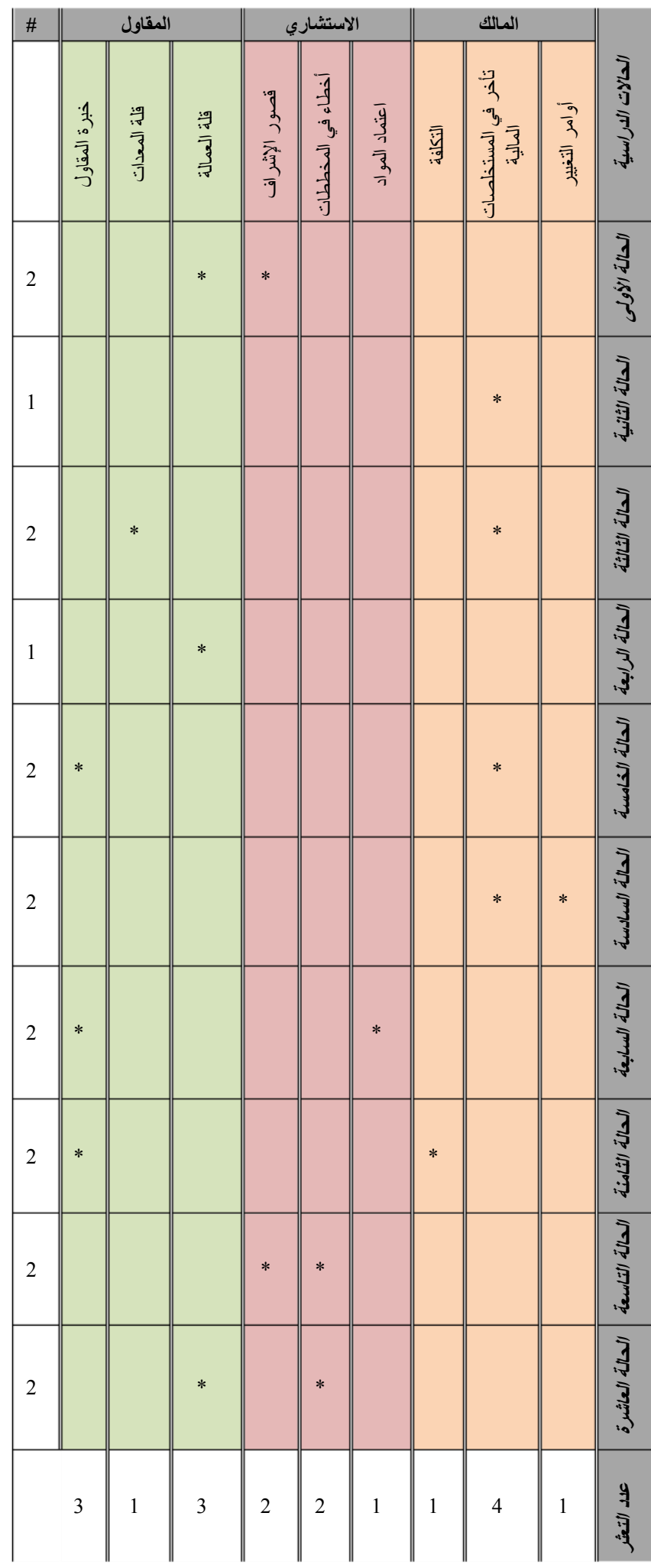

من خلال تحليل الحالات التي تمت مر اجعتُها، من الواضح أن أبرز المشاريع

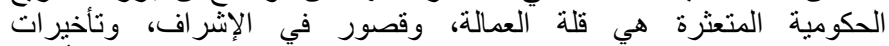

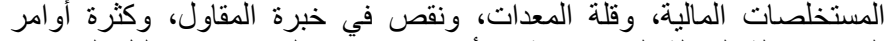

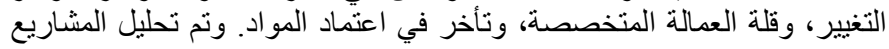

\begin{tabular}{|c|c|}
\hline الوصف & الحالة \\
\hline 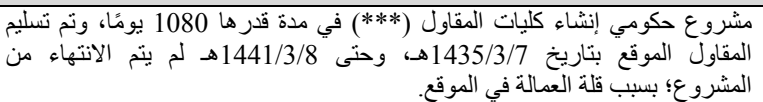 & الرابعة \\
\hline 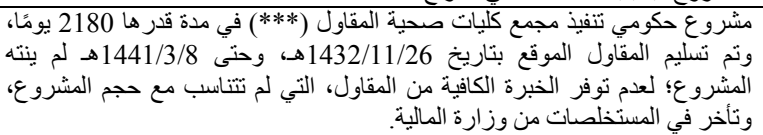 & الخامسلة \\
\hline 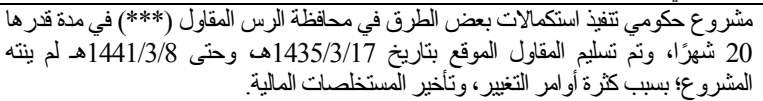 & السادسة \\
\hline 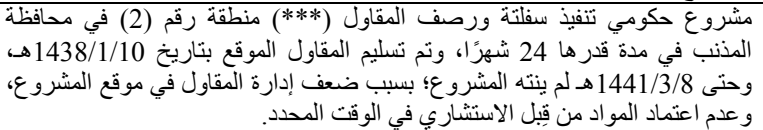 & السابعة \\
\hline 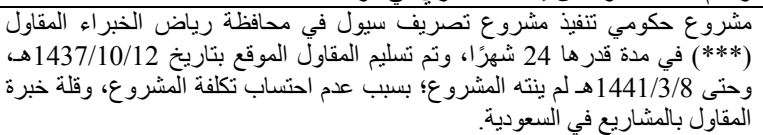 & الثامنة \\
\hline 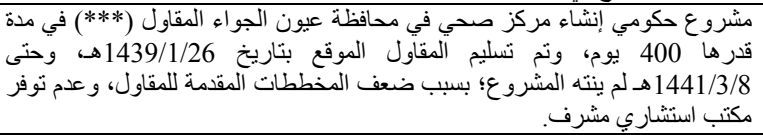 & التاسعة \\
\hline 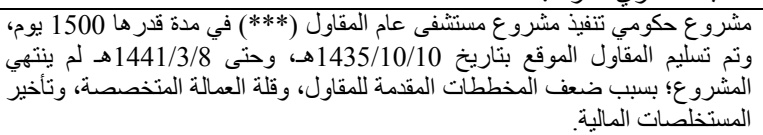 & العاشرة \\
\hline
\end{tabular}

من خلال تحليل الحالات الدراسية التي تمت زيارتها -وهي عشرة (10)

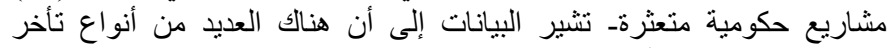

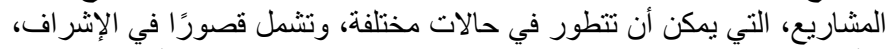

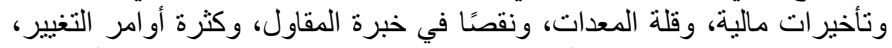

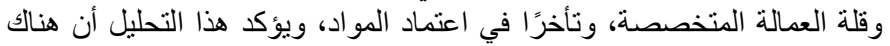

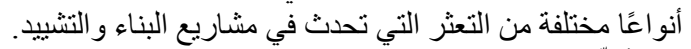

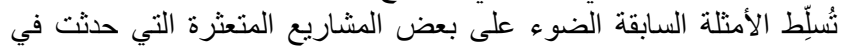

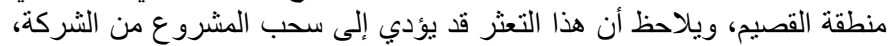

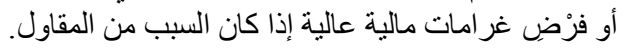

\section{XV}

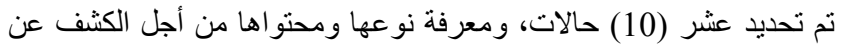

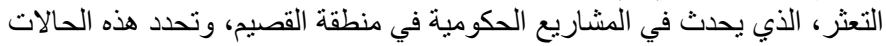

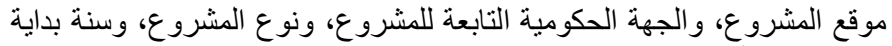
المشروع، وأسباب تعثر المشروع، ويبين الجدول رقم (3) ملخصنًا للحالات الدراسية.

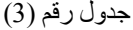

ملخص عن الحالات الدراسية

\begin{tabular}{|c|c|c|c|c|c|}
\hline أسباب التخثر & نوع المشروع & السنة & الحكمية & المنطقة & الحلة الثراسية \\
\hline الإثرة العملة وقصور في & مجمع سكي & 1432هـ & وزارة التعليم & مرينة & الحلة الأولى \\
\hline تلخر في المتتخصت & كليةطلبات & 1437هـ & وزارة التغليم & مبينة & الحلة الثنية \\
\hline المتلة المعدات وتأخز & بنيةتحنية & 1434هـ & وزارة التعليم & مبينة & الحلة الثلثة \\
\hline فلة العملة & كليةطلبات & 1436هـ & وزارة التعليم & مبينة & الحلة الرابعة \\
\hline خبرة المقلولوملية & كليةصحية & 1432 & وزارة التعليم & مرينة & الحلة الخلمسة \\
\hline 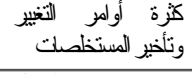 & استكمالاتطرق & 1435هـ & وزارة النظل & الزس محظة & الحلة السلسة \\
\hline 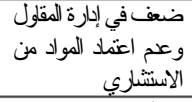 & سفلتةورصف & 1438 & القصيحة منطقة & المنب & الحلة السبعة \\
\hline 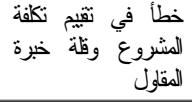 & تصريف سيول & 1437هـ & القصيم منطقة & محلظة & الحلة الثلمنة \\
\hline 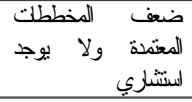 & مزكز صحي & 1439هـ & وزارة لصحة & محافظة & الحلة التلسعة \\
\hline
\end{tabular}


المتعثرة وتصنيفها إلى فئات، كما هو موضح في جدول (5)، ويشرح الجدول

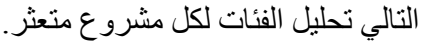

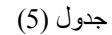

أنو اع تعثر المثاريع الحكومية في منطقة القصيم

\begin{tabular}{|c|c|c|c|c|c|c|c|c|c|c|}
\hline \multicolumn{4}{|c|}{ المقاول } & \multicolumn{3}{|c|}{ الانشتري } & \multicolumn{3}{|c|}{ الملك } & \multirow[b]{2}{*}{ لحالات اللرامية } \\
\hline \# & خلبرة & المعدات & العملة & الإثرن & لالخطاء في & اعتد المواد & التكلة & 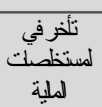 & ؤلمر التنييد & \\
\hline 2 & & & $*$ & $*$ & & & & & & لحلة الأولى \\
\hline 1 & & & & & & & & $*$ & & لحلة الثلية \\
\hline 2 & & $*$ & & & & & & $*$ & & لحلة الثلثة \\
\hline 1 & & & $*$ & & & & & & & لحلة للرابعة \\
\hline 2 & $*$ & & & & & & & $*$ & & لحلة الخمسة \\
\hline 2 & & & & & & & & $*$ & $*$ & لحلة لسلسة \\
\hline 2 & $*$ & & & & & $*$ & & & & الحلة لسلعة \\
\hline 2 & $*$ & & & & & & $*$ & & & لحلة التلنذة \\
\hline 2 & & & & $*$ & $*$ & & & & & الحلة التلنعة \\
\hline 2 & & & $*$ & & $*$ & & & & & لحلة العثلُة \\
\hline & 3 & 1 & 3 & 2 & 2 & 1 & 1 & 4 & 1 & علد التخز \\
\hline
\end{tabular}

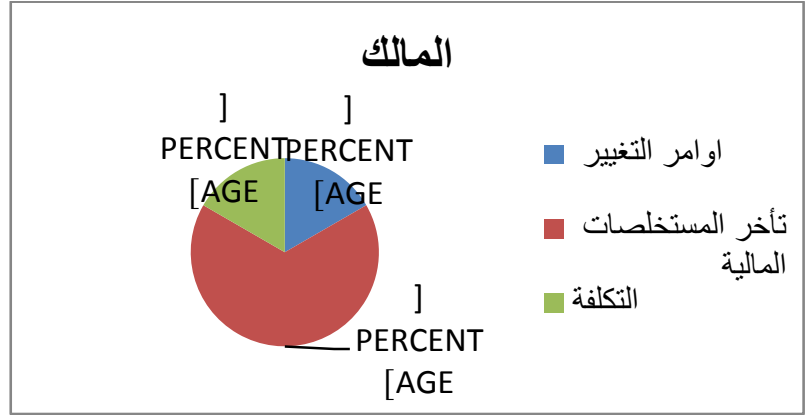

(2) الثكل رقم

نسبة أسباب التأخير فيما يخص المالك

ويوضح الثكل رقم (3) النسبة المئوية التي حثت في فئة الاستشاري؛ (20\%) (20)

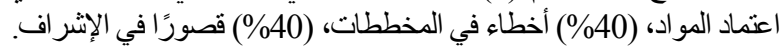

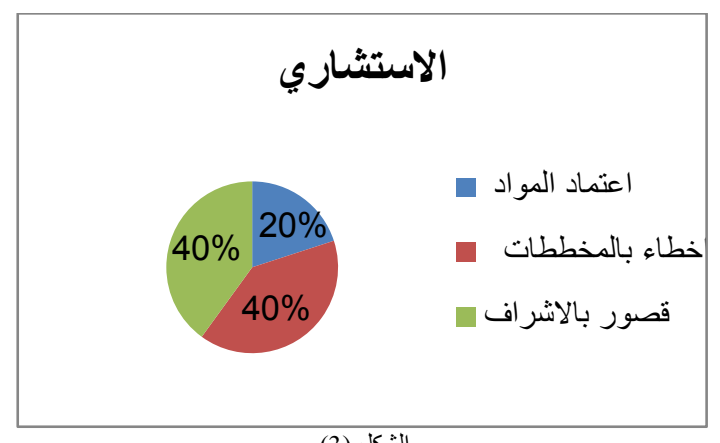

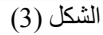

نسبة أسباب التأخير فيما يخص الاستثاري

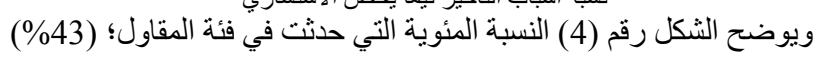

قلة العمالة، (14\%) قلة المعدات، (43) (4) قلة خبرة المقاول.
عكست فئة المالك 5 حالة من حالات تعثر المشاريع الحكومية في منطقة

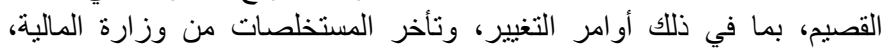

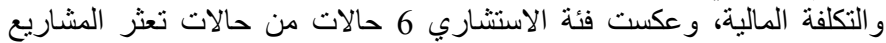

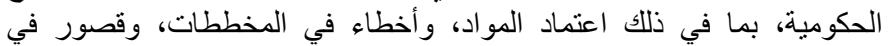

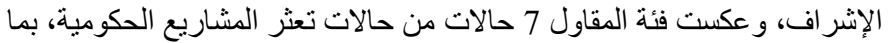

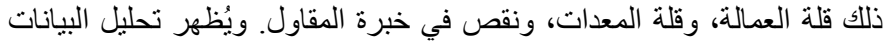

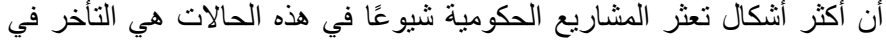

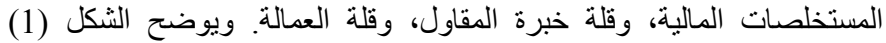

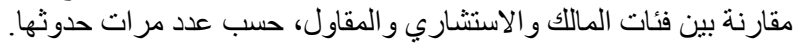

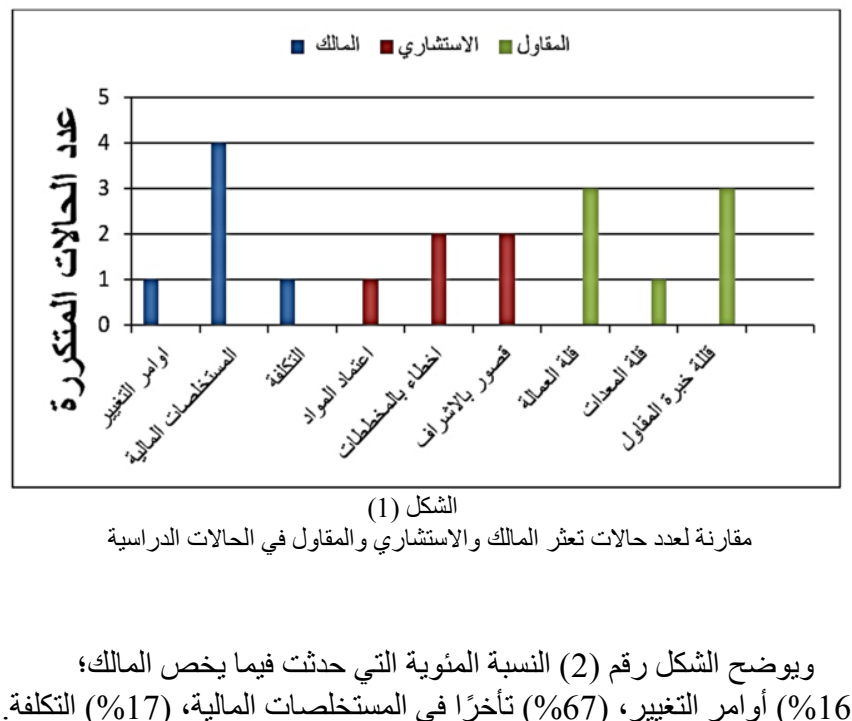


ذللك أعمال اللياسة، وأعمال المباني، وأعمال البلاط، وأعمال السقف المستعار،

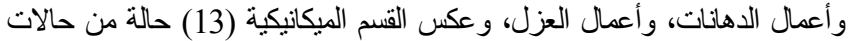

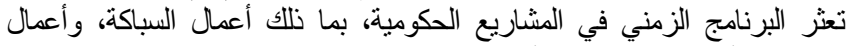

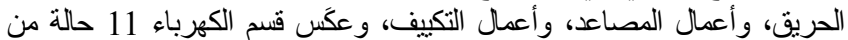
حالات تعثر البرنامج الزمني في المشاريع الحكومية، بما في في ذلاع ألك أعمال الإنارة،

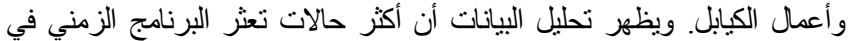

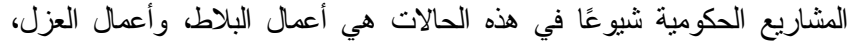

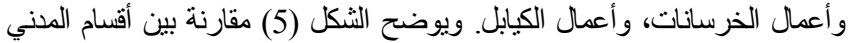
و المعماري والميكانيكية والكهرباء، حسب واعب عدد مرات حدوثها.

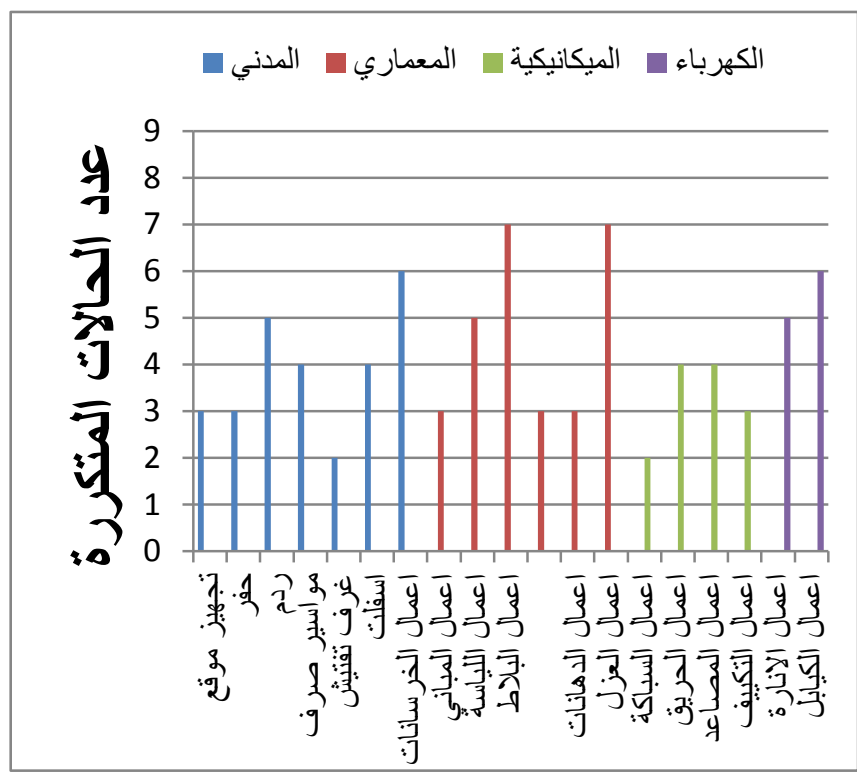

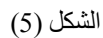

مقارنة لعدد حالات تعثر المدني و المعماري والميكانيكية و الكهرباء في الحالات الدراسية

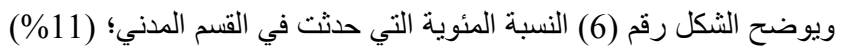

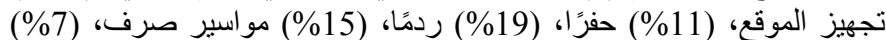
غرف تفتيش، (15\%) أسفلت، (22\%) (2) أعمال الخرسانات.

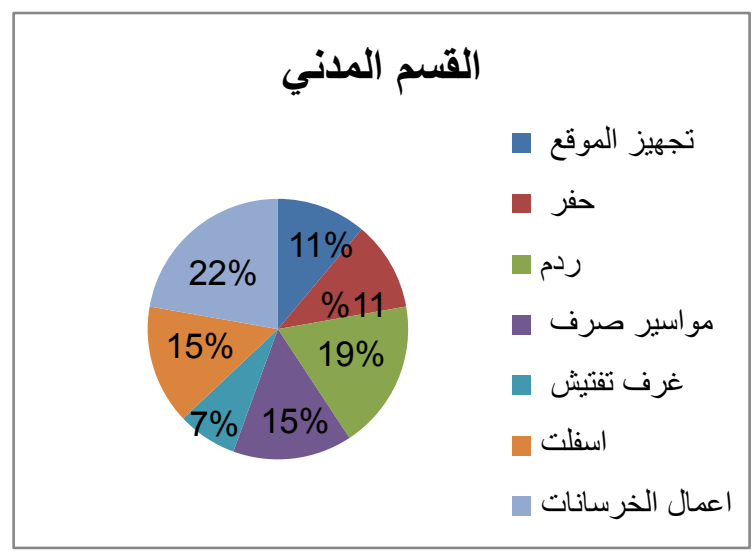

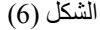

نسبة حالات القسم المدني حسب النوع

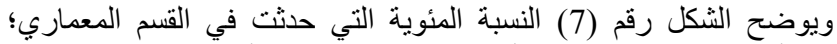

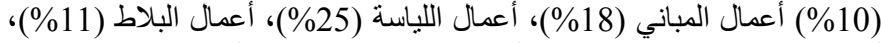
أعمال السقف المستعار، (11\%) أعمال الدهانات، (25\%) أعمال العزل.

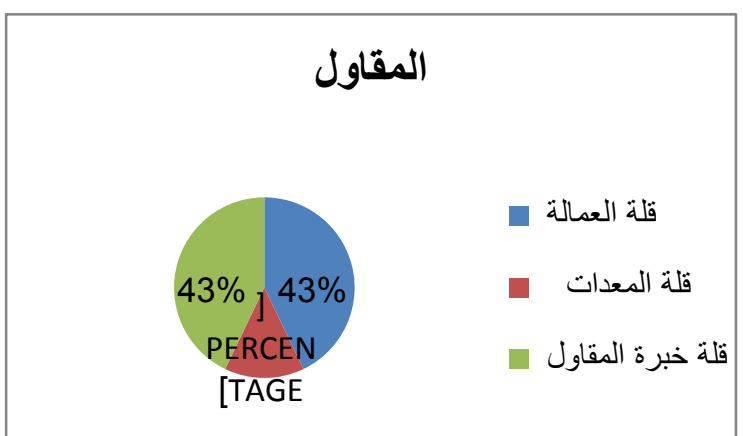

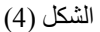

نسبة أسباب التأخير فيما يخص المقاول

وبمقارنة البيانات بين الأشكال (2،3،4) يمكن معرفة نسبة تعثر ، التي تحدث

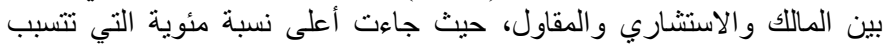

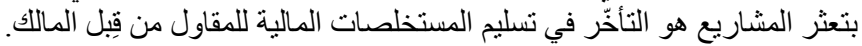

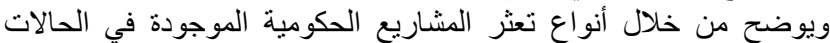

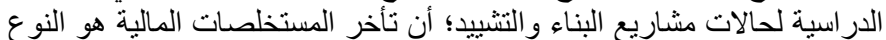

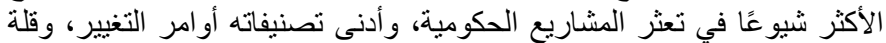

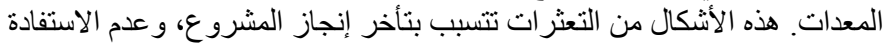

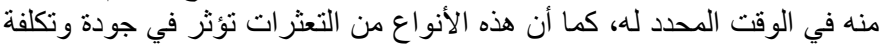

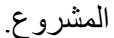
ومن حيث مراجعة البرنامج الزمني للمشاريع المتعثر؛ تم تحديد 19 نوعًا

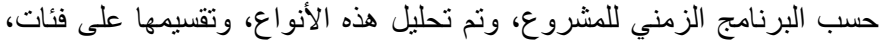

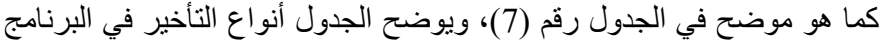
الزمني للمشاريع المتعثرة.

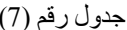
تحليل أنو اع التأخير في البرنامج الزمني للمشاريع المتعثرة للحالات الدراسية

\begin{tabular}{|c|c|c|c|c|c|c|c|c|c|c|c|}
\hline \multirow[b]{2}{*}{ 年 } & \multicolumn{10}{|c|}{ الحالات الدراسية } & \multirow[b]{2}{*}{ وصف النوع } \\
\hline & $\stackrel{3}{\stackrel{3}{2}}$ & $\frac{\text { 赵 }}{\text { के }}$ & $\frac{3}{\infty}$ & 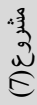 & & $\frac{3}{2}$ & 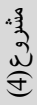 & $\frac{3}{3}$ & $\frac{\text { aे }}{\stackrel{3}{\alpha}}$ & 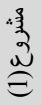 & \\
\hline 3 & & & & * & & * & & & & $*$ & تجيزيز الموقع \\
\hline 3 & & & & & * & & * & & * & & حفز \\
\hline 5 & & & * & * & * & & & * & & $*$ & رم \\
\hline 4 & * & & * & & & & & * & & $*$ & مواسير صرف \\
\hline 2 & & & * & & & & & $*$ & & & غرف تهنيش \\
\hline 4 & & & $*$ & $*$ & $*$ & & & $*$ & & & أسفقت \\
\hline 6 & * & $*$ & * & * & & $*$ & & & & $*$ & الخرستات \\
\hline 3 & * & & & & & & * & & * & & أعمل المبلي \\
\hline 5 & $*$ & $*$ & & & & * & * & & * & & أعمل الليلسة \\
\hline 7 & * & $*$ & & $*$ & & $*$ & * & & $*$ & $*$ & أعمل البلاط \\
\hline 3 & & $*$ & & & & * & & & & $*$ & السق المستعلر \\
\hline 3 & & * & & & & & * & & * & & أعمل الدهلتات \\
\hline 7 & * & * & & & & * & $*$ & * & * & $*$ & أعمل العزل \\
\hline 2 & $*$ & & & & & $*$ & & & & & أعمل السبكة \\
\hline 4 & $*$ & $*$ & & & & * & & & & $*$ & أعمل الحريق \\
\hline 4 & * & $*$ & & & & & * & & * & & أعمل مصاعد \\
\hline 3 & & * & & & & * & & & & $*$ & أعل تكيف \\
\hline 5 & $*$ & $*$ & & & & & $*$ & $*$ & $*$ & & أعمل إنارة \\
\hline 6 & $*$ & & * & & * & $*$ & & $*$ & & $*$ & أعمل كيلبل \\
\hline & 11 & 10 & 6 & 5 & 4 & 10 & 8 & 7 & 8 & 10 & $\#$ \\
\hline
\end{tabular}

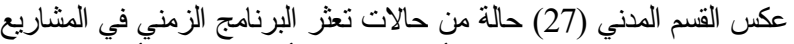

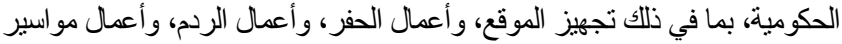

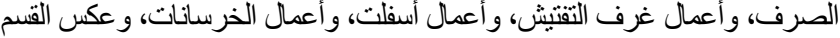
المعماري (28) حالة من حالات تعثر البرنامج الزمني في المشاريع الحكومية، بما في وعي 


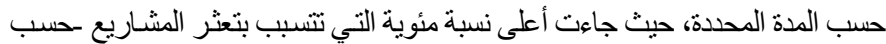

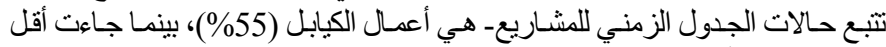
نسبة مئوية في أعمال المباني (10\%).

XVI

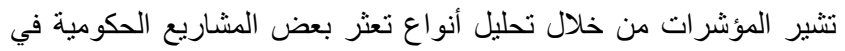

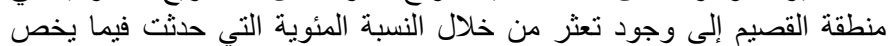
المالك؛ (16\%) أو امر التغيير، (67\%) تأخرًا في المستخلصات المالية، (17\%) التكلفة.

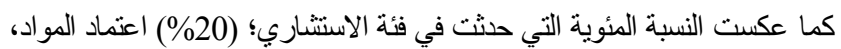

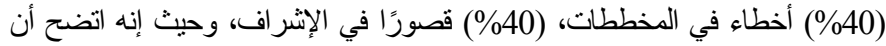
النسبة المئوية التي حدثت في فئة المقاول؛ (43\%) قلة فئة العمالة، (14\%) قلة المعدات، (43\%) قلة خبرة المقاول.

\section{XVII}

يتضح من خلال تحديد وتحليل أنواع تعثر المشاريع الحكومية في منطقة

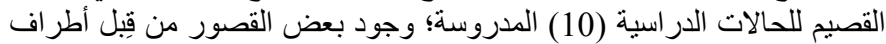

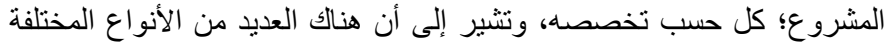

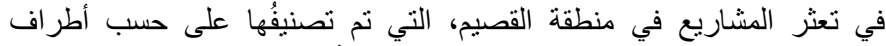

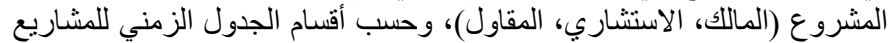

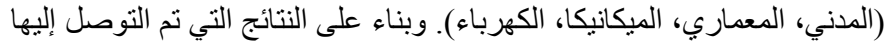

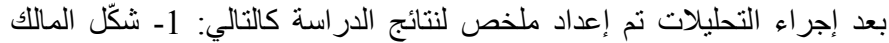

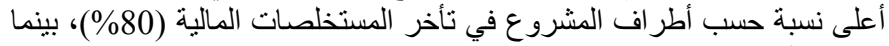

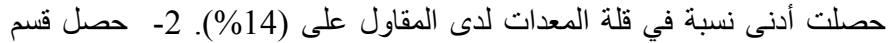

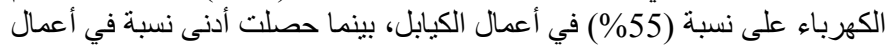

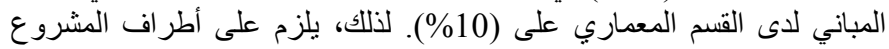

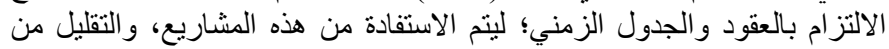

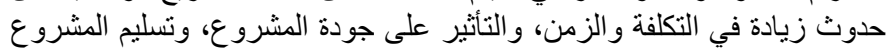

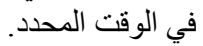

\section{XVIII}

ضروره دراسه المشاريع بصوره جديه قبل البدء بالمشروع ووضع

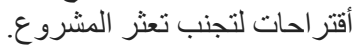

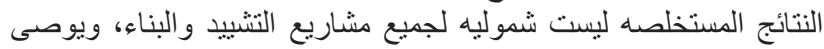

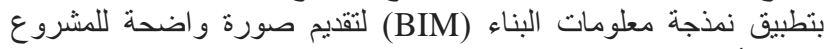
وجميع أطر اف المشروع معنومات وتجنب التعثر في المشاريع.

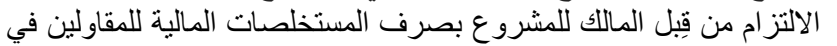

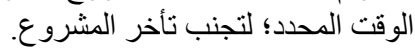

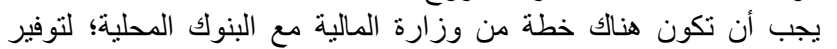

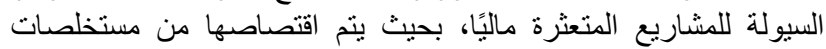
المقاولين. يجب إنشاء منصة عمل للربط بين مشاريع الدولة، بحيث لا يتم ترسية أكثر من مشروع على نفس المقاول.

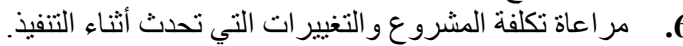

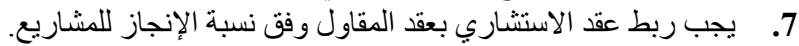
8.

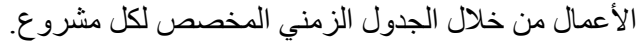
تدريب الكوادر السعودية؛ ليتم الاستفادة منها في الإشر اف لاف على المشاريع.

\section{المر اجع العربية}

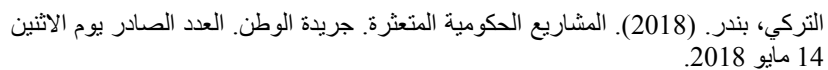

[2] Falqi, I. (2004). Delays in project completion: A comparative study of construction delay factors in Saudi Arabia and the United Kigdom. Unpublished MSc dissertation, Edinburgh: Heriot-Watt University. http://www.arcom.ac.uk/-docs/proceedings/ar2012-1003-

1012_Alsuliman_Bowles_Chen.pd.

.3

.4

.5 6

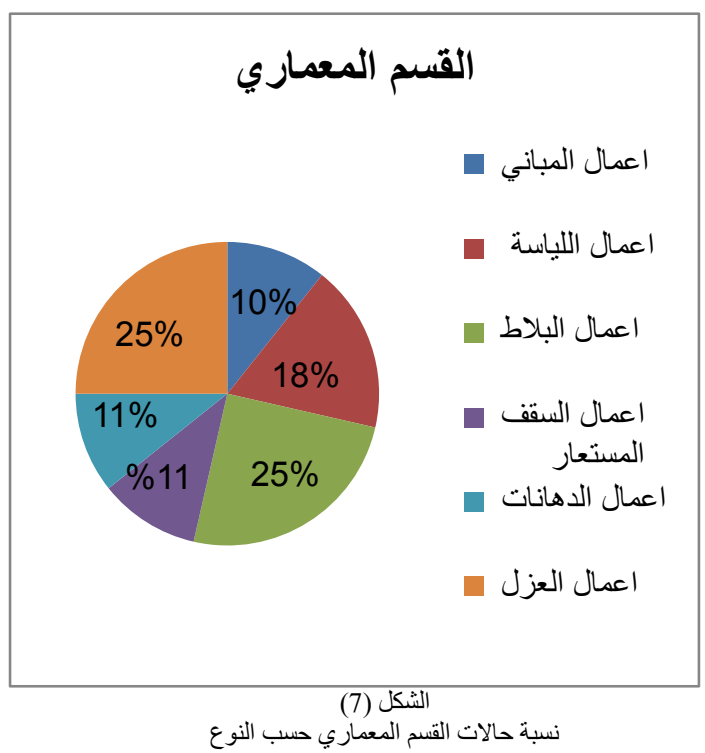

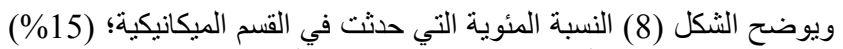

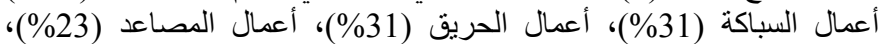
أعمال التكييف. أعمال.

\section{القسم الميكانيكية}

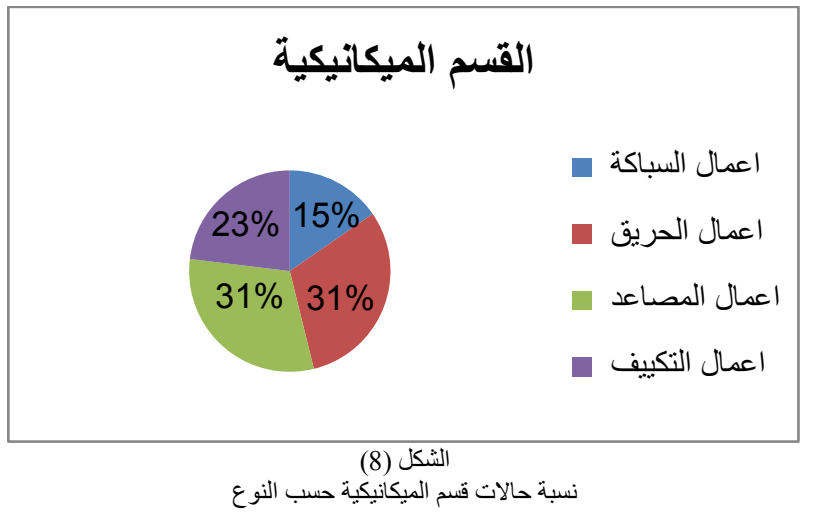

ويوضحح الثكل (9) النسبة المئوية التي حدثت في قسم الكهرباء؛ (45\%) أعمال الإنارة، (55\%) أعمال الكيابل. (n)

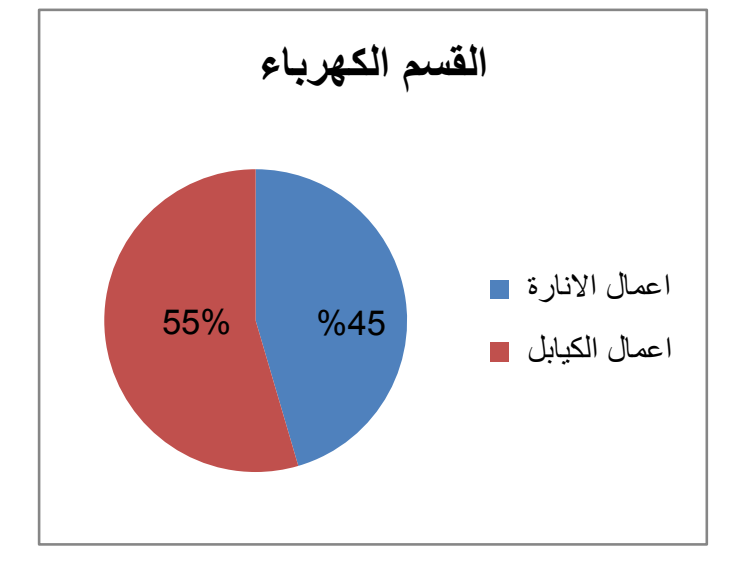

$$
\text { نسبة حالات قسم الكهرباء حسب النوع }
$$

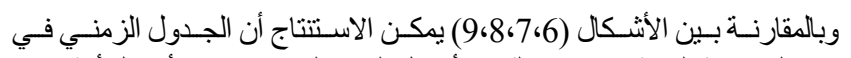

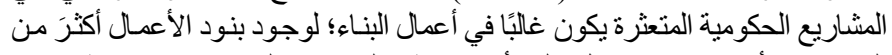

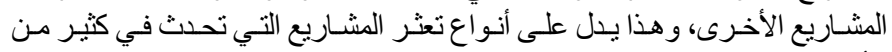

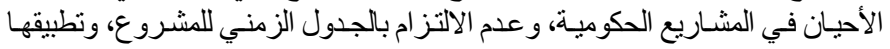


[16] سوركتي، شيماء. (2016). الأوامر التغييرية و أثر ها على المطالبات في عقد التشييد.

[17] [17] محل، سامح. (2008). الإدارة و الهندسة الصناعية. مصر: دار النشر للجامعات.

[18] Baguley, P. (2010). Improve Your Project Management: Teach Yourself. Hachette UK.

Title in Arabic:

$$
\text { (الاتواع دعثر المشاريع الحكومية) }
$$

\section{Abstract in Arabic:}

يعتبر قطاع البناء والتشييد في المملكة العربية السعودية من أهم القطاعات، ومع

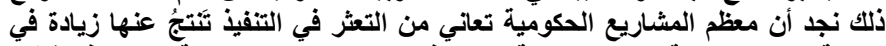

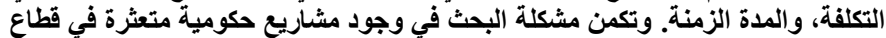

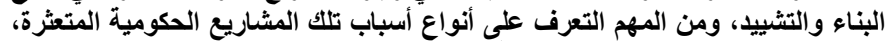

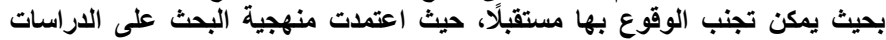

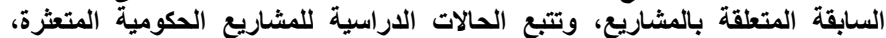

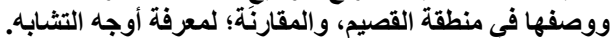

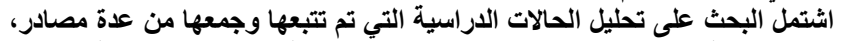

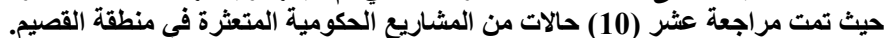

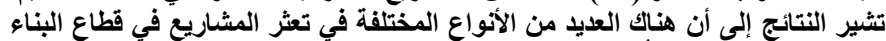

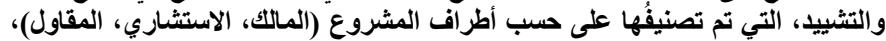

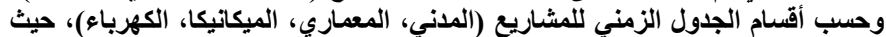

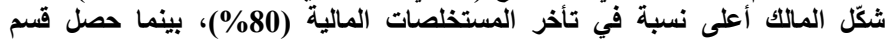

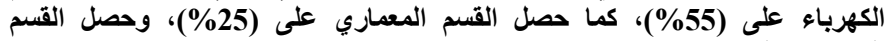
الميكانيكا على (\%31\%).
[3] Kanoglu, A. (2003). An integrated system for dura on es ma on in design/build project organizations. Engineering Construction and Architectural Management, Volume 10 , Number http://www.iasdm.org/journals/index.php/ijaec/article/view/139/112.pdf.

[4] Bechtel, Cbillc . (2018). Saudi Arabia construction market - growth, trends, and forecast (2019 - 2024). https://www.mordorintelligence.com/industryreports/saudi-arabia-construction-market-growth-trends-and-forecast-2019-2024

[5] Elawi, Ghazi. (2015). owners' perspective of factors contributing to project delay: case studies of road and bridge projects in Saudi Arabia. https://www.sciencedirect.com/ science/article/pii/S1877705816301837

[6] Mahamid, Ibrahim; Al-ghonamy, A; Aichouni , M.(2015). Risk matrix for delay causes in construction projects in Saudi Arabia.

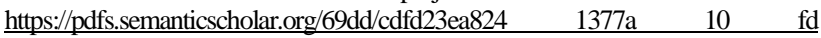
942b5817ed106da6.pdf

[7] Albogamy, Abdullah; Scott, Darren; Dawood, Nashwan .(2013). dilemma of Saudi Arabian construction industry. https://www.researchgate.net/publication/264139569 Dilemma of Saudi Arabian Construction Industry

[8] Al-Kharashi, Adel; Skimore, Martin. (2009). Causes of delays in Saudi Arabian public sector construction projects. https://www.researchgate.net/publication/ 46529109 Causes of delays

in Saudi Arabia public sector construction projects

[9] Al-Dmaidi, Nabil. (2013). time overrun causes in public construction projects in Saudi Arabia: contractors view. https://staff-old.najah.edu/nabil/publishedresearch/time-overrun-causes-public-construction-projects-saudi-arabiacontractors\%E2\%80\%99-

[10] ] المحيميد، ناصر. (2017). إدارة المشاريع الاحتر افية. الرياض: مكتبة الملك فهد الوطنية.

[11] Olivla ， Labarre (2019)."Project Management https://www.pmi.org/about/learn-about-pmi /what-is-project-management .

[12] Abdulrahim, Mohammed. (2014). Project Management: Characteristics and risks. http://dr-ama.com/wp-content/uploads/2015/10/project-management-attributesand-Risks.pdf

[13] John, F.R. (2018). How to successfully manage your first project. https://www. Thebalancecareers.com/how-to-successfully-manage-your-first-project-2276127 [14] سوركتي، شيماء. (2016). الأو امر التغييرية وأثر ها على المطالبات في عقد التشييد.

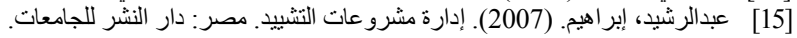

